\title{
MORREY SPACES ARE CLOSELY EMBEDDED BETWEEN VANISHING STUMMEL SPACES
}

\begin{abstract}
STEFAN SAMKO
Abstract. We prove a new property of Morrey function spaces by showing that the generalized local Morrey spaces are embedded between weighted Lebesgue spaces with weights differing only by a logarithmic factor. This leads to the statement that the generalized global Morrey spaces are embedded between two generalized Stummel classes whose characteristics similarly differ by a logarithmic factor. We give examples proving that these embeddings are strict. For the generalized Stummel spaces we also give an equivalent norm.
\end{abstract}

Mathematics subject classification (2010): Primary 46E15; Secondary 42B35.

Keywords and phrases: function space, local Morrey space, global Morrey space, generalized Morrey space, weighted space, Stummel class.

\section{REFERENCES}

[1] D. R. AdAMS, Lectures on $L^{p}$-potential theory, UmeåUniversity Reports, no. 2, 1981.

[2] T. AlvareZ AND C. PÉREZ, Estimates with $A_{\infty}$ weights for various singular integral operators, Boll. Un. Mat. Ital. A (7) 8, 1 (1994), 123-133.

[3] H. ARAi And T. Mizuhara, Morrey spaces on spaces of homogeneous type and estimates for $\square_{b}$ and the Cauchy-Szegö projection, Math. Nachr. 185, 1 (1997), 5-20.

[4] V. I. BuRENKov AND H. Guliyev, Necessary and sufficient conditions for boundedness of the maximal operator in local Morrey-type spaces, Studia Math. 163, 2 (2004), 157-176.

[5] Eridani And H. Gunawan, Stummel class and Morrey spaces, Southeast Asian Bull. Math. 29 (2005), 1053-1056.

[6] A. ERidani, V. KokilashVili, And A. Meskhi, Morrey spaces and fractional integral operators, Expo. Math. 27, 3 (2009), 227-239.

[7] M. Giaquinta, Multiple integrals in the calculus of variations and non-linear elliptic systems, Princeton Univ. Press, 1983.

[8] V. GULIYEV, Integral operators on function spaces on homogeneous groups and on domains in $R^{n}$, Doctor's Theses, Steklov Math. Inst. Moscow, 1994 (in Russian).

[9] V. GuliYev, Function spaces, integral operators and two weighted inequalities on homogeneous groups. Some applications, Baku, 1999 (in Russian).

[10] V. Guliyev, J. HaS AnOv, AND S. SAMKo, Maximal, potential and singular operators in the local “complementary" variable exponent Morrey type spaces, J. Math. Anal. Appl. 401, 1 (2013), 72-84.

[11] A. Kufner, O. John, AND S. Fuč IK, Function Spaces, Noordhoff International Publishing, Leyden, 1977.

[12] S. LeONARDI, Remarks on the regularity of solutions of elliptic systems, A. Sequeira, H. B. Veiga, and J. H. Videman, Editors, Applied Nonlinear Analysis, Kluwer, New York, 1999, 325-344.

[13] S. LEONARDI, Weighted Miranda-Talenti inequality and applications to equations with discontinuous coefficients, Comment. Math. Univ. Carolin. 43, 1 (2002), 43-59.

[14] D. LukKassen, L.-E. Persson And S. SAmko, Weighted Hardy operators in complementary Morrey spaces, J. Funct. Spaced Appl., to appear.

[15] E. NAKAI, Hardy-Littlewood maximal operator, singular integral operators and the Riesz potentials on generalized Morrey spaces, Math. Nachr. 166 (1994), 95-103. 
[16] H. RAFEIRo, N. SAMKo, AND S. SAmKo, Morrey-Campanato spaces: an overview, In Oper. Theory, PDE and Math. Phys. Operator Theory: Advances and Applications, Birkhäuser, 228 (2013), 293324.

[17] M. A. Ragusa And P. Zamboni, A potential theoretic inequality, Czech. Math. J. 51 (126) (2001), $55-65$.

[18] F. Stummel, Singuläre elliptische Differential-operatorenin Hilbertschen Räumen, Math. Ann. 132 (1956), 150-176.

[19] M. E. TAYLOR, Tools for PDE: Pseudodifferential Operators, Paradifferential Operators, and Layer Potentials, volume $\mathbf{8 1}$ of Math. Surveys and Monogr., AMS, Providence, R. I. 2000.

[20] C. T. Zor Ko, Morrey space, Proc. Amer. Math. Soc. 98, 4 (1986), 586-592. 